\title{
INORGANIC PARTICLES PRODUCED BY MICROORGANISMS
}

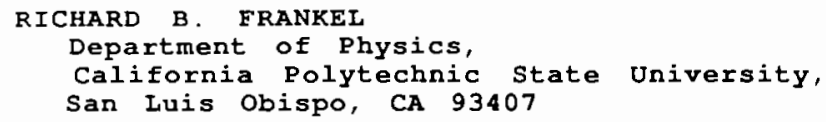

\section{ABSTRACT}

The processes by which microorganisms, particularly bacteria, produce inorganic mineral particles are reviewed.

\section{INTRODUCTION}

Biomineralization processes by which organisms form inorganic minerals are broadly distributed and occur in almost every phylum of the biological world [1-5]. There is a large diversity of minerals formed, with over 60 currently known [1]. Microorganisms, including eukaryotes (fungi, protozoa and algae) and prokaryotes (bacteria), are deeply involved in the geochemical cycling of inorganic elements via mineral formation and diagenesis. Biomineralization products include calcium carbonates, calcium phosphates, silica, iron oxides, manganese oxides, iron phosphates, iron sulfides, and other heavy metal sulfides. The potency of bacteria in biomineralization is due to their high surface to volume ratio and to the negatively charged moieties that constitute their cell walls and are potential sites for the binding of cations [6].

\section{BIOMINERALIZATION}

Lowenstam [7] has distinguished two general modes of biomineraliztion, namely, biologically-induced mineralization (BIM) and biologically controlled mineralization (BCM) (also referred to as boundary-organized biomineralization (BOB) [8]). In a BIM process, cellular export of metabolic products results in extracellular mineral formation with ions in the environment. The particles are essentially indistinguihable from those produced by purely inorganic processes. In a BCM process, the mireral phase is deposited in or on preformed organic vesicles or matrices produced by the organism. BIM processes are not controlled by the organism and the mineral particles typically have a large size distribution and no unique morphology. BCM processes involve highly controlled mineralization and the particles often have a narrow size distribution and species-specific morphology. Much of the current research on biomineralization phenomena is directed at elucidating the structure of the organic macromolecules involved in the BCM processes and the nature of the organic-inorganic interactions.

In a very general way, all iron oxidation by molecular oxygen on the surface of the earth occurs by a BIM process because molecular oxygen in the atmosphere is a byproduct of photosynthesis. However, the distinction between BIM and BCM processes is more useful in considering more restricted situations, such as instances of iron biomineralization by bacteria. 
Magnetite $\left(\mathrm{Fe}_{3} \mathrm{O}_{4}\right)$ formation by bacteria occurs by both BIM and $\mathrm{BCM}$ processes, in dissimilatory iron-reducing bacteria and magnetotactic bacteria, respectively. The dissimilatory ironreducing bacteria [9] respire $\mathrm{Fe}^{3+}$ obtained from ferric oxyhydroxide in the environment, that is, they use ferric ions as terminal electron acceptors in their metabolism. The resulting ferrous ions are exported into the environment where they interact with excess ferric oxy-hydroxide to produce magnetite by a BIM process. The ferrous ions can also interact with carbonate in the medium to form ferrous carbonate, siderite [10]. In contrast. magnetotactic bacteria form magnetite particles [11,12] by a $B C M$ process in intracellular membrane vesicles [13] from a ferric oxyhydroxide precursor and ferrous ions [14] A particle and its enveloping membrane is known as a magnetosome, and the process is presumably mediated by the magnetosome membrane. The particles constitute a permanent magnetic dipole in each cell that is the basis of the magnetotactic response.

The structures and magnetic properties of the magnetite particles produced by the BIM and BCM processes noted above have characteristic differences $[10,15]$. In the case of the dissimilatory iron reducing bacteria, the particles have a broad size distribution and no apparently preferred morphology. The magnetite particles produced by magnetotactic bacteria on the other hand, have a narrow size distribution and species-specific morphologies. Under certain culture conditions, magnetotactic bacteria produce extracellular ferrous phosphate, vivianite [16], presumably by a BIM process.

Iron sulfide formation by bacteria also occurs by both BIM and BCM processes, with sulfate-reducing bacteria in marine sediments $[17,18]$ and magnetotactic bacteria from high sulfide environments $[19,20]$, respectively. Extracellular iron sulfides are produced by BIM processes in marine sediments as a byproduct of bacterial sulfate reduction (respiration) and export of sulfide ions. This results in a mixture of iron sulfides, including material known as framboidal iron pyrites [17]. In contrast, intracellular crystalline particles of the iron sulfides greigite and pyrite [19], and pyrrhotite [20], have been reported in magnetotactic bacteria from marine salt ponds with high sulfide concentrations. The particles are related to the magnetotactic response of these organisms, and possibly to other, metabolic, functions as well. Some types of the magnetotactic bacteria contain greigite particles (without pyrite) with species-specific morphologies [21], suggesting BCM processes.

Eerric oxy-hydroxides are produced both extracellularly and intracellularly by bacteria. Extracellular production occurs in the case of the so-called iron bacteria [4] which utilize oxidation of ferrous ions by molecular oxygen as an energy source, resulting in the export and subsequent hydrolysis of ferric ions. Intracellular production occurs as mineral core particles in the iron storage proteins known as bacterioferritins [22]. In the latter case the mineral particles are associated with phosphate. It is tempting to characterize the extra- and intracellular production as BIM and BCM processes, respectively. However. the formation of ferric oxy-hydroxides by the iron-bacteria has some characteristics of a BCM process. While the mineral particles themselves are indistinguishable from particles formed by purely inorganic hydrolysis the precipitate is molded into sheaths and 
stalks, presumably by organic molecules on the outer surfaces of the cells.

Biologically controlled mineralization of iron minerals in bacteria is as refined and highly developed as the mineralization processes in higher organisms, and could have commenced very early in the history of life. It is not inconceivable that elucidation of biomineralization processes in bacteria at the physiological and genetic levels could lead to the manipulation of those processes, and eventually to the bioengineering of submicron inorganic particles in bacteria.

\section{REFERENCES}

1. H.A. Lowenstam and S. Weiner, on Biomineralization (Oxford University Press, Oxford, 1989) 324 pages.

2. K. Simkiss and K.M. Wilbur, Biomineralization (Academic Press, N.Y., 1989) 337 pages.

3. S. Mann, J. Webb and R.J.P. Williams, Editors, Biomineralization (VCH, Weinheim, 1989) 541 pages.

4. H.L. Ehrlich (1981) Geomicrobiology (Dekker, New York, 1981) 393 pages.

5. R.B. Frankel and R.P. Blakemore, Editors, Iron Biominerals (Plenum Press, New York, 1990) 417 pages.

6. T.J. Beveridge, Canad. Jour. Microbiol. 34, 363 (1988).

7. H.A. Lowenstam, Science 244, 126 (1981).

8. S. Mann, J.Inorg. Biochem. 28, 363 (1986).

9. D.R. Lovley, J.F. Stoltz, G.I. Nord, Jr., and E.J.P. Phillips, Nature (London) 330, 252 (1987).

10. N.H.C. Sparks, S. Mann, D.A. Bazylinski, D.R. Lovley, H.W. Jannasch, and R.B. Frankel, Earth Planet. Sci. Letters 9814 (1990).

11. R.B. Frankel, R.P. Blakemore, and R.S. Wolfe, Science 203, 1355 (1979).

12. D.A. Bazylinski, R.B. Frankel and H.W. Jannasch, Nature (London) 334, 518 (1988).

13. Y. Gorby, T.J. Beveridge, and R.P. Blakemore, J. Bacteriol. $170,834(1988)$.

14. R.B. Frankel, G.C. Papaefthymiou, R.P. Blakemore and W.D. O'Brien, Biochim. Biophys. Acta 736, 147 (1983).

15. B.M. Moskowitz, R.B. Frankel, D.A. Bazylinski, H.W. Jannasch and D.R. Lovley, Geophys. Res. Lett. 16, 665 (1989)

16. R. P. Blakemore, and R. B. Frankel, in Metal-Microbe Interactions, edited by R. K. Pool and G. Gadd ( I R L Press, Oxford, 1989) p.85.

17. P. A. Trudinger, I. B. Lambert, and G. W. Skyring Econ. Geol. 67, 1114 (1972).

18. H.E. Jones, P.A. Trudinger, L.A. Chambers and N.A. Pyliotis, Z. Allg. Mikrobiol. 16, 425 (1976).

19. S. Mann, N.H.C. Sparks, R.B. Frankel, D.A. Bazylinski, and W. Jannasch, Nature (London) 343, 258 (1990).

20. M. Farina, H.G.P. Lins de dBarros, and D.M.S. Esquivel, Nature (London) 343, 256 (1990).

21. B.R. Heywood, D.A. Bazylinski, A.J. Garratt-Reed, S. Mann, and R.B. Frankel, Naturwissenschaften, in the press, 1990.

22. E. I. Stiefel and G. D. Watt, Nature (London) 279, 81 (1979). 